\title{
CONHECIMENTOS E POSICIONAMENTOS DE ADOLESCENTES SOBRE DOAÇÃO DE ÓRGÃOS ANTES E APÓS UMA AÇÃO EDUCATIVA
}

\author{
KNOWLEDGE AND POSITIONING OF TEENAGERS ABOUT ORGAN \\ DONATION BEFORE AND AFTER AN EDUCATIONAL ACTION
}

\section{CONOCIMIENTO Y POSICIONES DE ADOLESCENTES SOBRE DONACIÓN DE ÓRGANOS ANTES Y DESPUÉS DE ACTIVIDAD EDUCATIVA}

\author{
Maicon de Araujo Nogueira ${ }^{1}$, Danielle Oliveira Maciel $^{2}$, Jéssica Adriana Barbosa Dias ${ }^{3}$, \\ Thayná Desireé Rodrigues Martins ${ }^{4}$, Márcio Almeida Lins ${ }^{5}$, Karla Christina Bernardes ${ }^{6}$, \\ Marcos Renan Miranda Neres ${ }^{7}$, Antônia Margareth Moita Sá ${ }^{8}$
}

\begin{abstract}
RESUMO
Objetivo: analisar o conhecimento dos adolescentes sobre doação e transplante de órgãos antes e após uma ação educativa. Método: pesquisa descritiva, exploratória com abordagem quanti-qualitativa, alicerçada na Pesquisa-Ação. Participaram do estudo 45 adolescentes do ensino médio de uma escola privada de Belém-Pa. Foi aplicado um questionário antes e após uma intervenção educativa, com posterior análise comparativa das respostas. Resultados: a idade variou de 13 a 17 anos, a maioria 26 (57,8\%) do gênero feminino, católicos $33(73,3 \%)$. Houve aumento significativo das respostas adequadas, confirmando que a educação em saúde promove o conhecimento e esclarecimento, despertando o interesse pelo assunto e discussão no meio social. Conclusão: a educação em saúde é uma grande aliada na promoção de doação de órgãos e tecidos. Após a ação, houve o aumento nível de conhecimento, diminuição nas dúvidas existentes e mudanças no posicionamento, optando a maioria em ser doador e consentir a doação.
\end{abstract}

Descritores: Obtenção de tecidos e órgãos; Educação em saúde; Adolescentes.

\begin{abstract}
Objective: To analyze the perception of teenagers about organ donation and transplantation before and after an educational activity. Method: descriptive, exploratory research with quantitative and qualitative approach, based on Action Research. The study included 45 high school students from a private school in Belém-Pa. We applied a questionnaire before and after an educational intervention with subsequent comparative analysis of responses. Results: ages ranged from 13 to 17 years, the majority $26(57.8 \%)$ were female, Catholic $33(73.3 \%)$. There was a significant increase in appropriate responses, confirming that health education promotes knowledge and enlightenment, awakening interest in the subject and discussion in the social environment. Conclusion: health education is a great ally in promoting organ donation. After

\footnotetext{
1 Enfermeiro. Especialista em Urgência e Emergência. Universidade do Estado do Pará - UEPA, Belém-Pa. Email: enfnogueira@globomail.com

2 Enfermeira. Universidade do Estado do Pará - UEPA, Belém-Pa. E-mail: oliveira.danimac@ gmail.com

3 Enfermeira. Universidade do Estado do Pará - UEPA, Belém-Pa. E-mail: jessicabarbosa25@ gmail.com 4 Acadêmica de enfermagem da Universidade do Estado do Pará. Email: thayna_desiree@hotmail.com 5 Acadêmico de enfermagem. Faculdade Metropolitana da Amazônia-FAMAZ, Belém, PA, Brasil. E-mail: enflins@gmail.com

6 Enfermeira. Universidade do Estado do Pará - UEPA, Belém-Pa. E-mail: enf.karlabernardes@gmail.com 8 Enfermeira pela Universidade Federal do Pará), mestrado em Enfermagem pela Universidade Federal do Rio de Janeiro, doutorado em Enfermagem pela Universidade Federal do Rio de Janeiro. Professora adjunto IV da Universidade do Estado do Pará, enfermeira assistente - Secretaria de Estado de Saúde Pública.
} 7 Enfermeiro. Universidade do Estado do Pará - UEPA, Belém-Pa. E-mail: marcos.renan1993@gmail.com
\end{abstract}


the action there was an increase in knowledge of the rate on the subject, decrease in doubts and changes in positioning, where most wished to be a donor.

Keywords: Tissue and organ procurement; Health education; Teenagers.

\section{RESUMEN}

Objectivo: analisar la percepción de los adolescentes sobre donación y transplate de órganos antes y después de una ación educativa. Método: estudio descriptivo, exploratório, cuantitativo y cualitativo, basado em la investigación-acción. El estudio incluyó a 45 estudiantes de la escuela secundaria de una escuela privada en Belém-Pa. Se aplicó un cuestionario antes y después de una intervención educativa con posterior análisis comparativo de las respuestas. Resultados: la edad varió de 13 a 17 años, la mayoría $(57,8 \%)$ eran mujeres, católica $(73,3 \%)$. Hubo un aumento significativo en las respuestas adecuadas, lo que confirma que la educación em salud promueve el conocimiento. Conclusión: la educación en salud es un gran aliado en la promoción de donación de órganos y tejidos. Después de la acción, hubo un nivel de aumento de los conocimientos, la disminución de las dudas y los cambios en el posicionamiento, la elección de los más en ser un donante.

Descriptores: Obtención de tejidos y órganos; Educación em salud; Adolescentes.

\section{INTRODUÇÃO}

Transplante é a retirada parcial ou total de uma estrutura corpórea ou órgão e seu implante na mesma pessoa ou em outro indivíduo. É descrito como um procedimento que oportuniza reabilitação e aumento da expectativa de vida, atualmente reconhecido como uma terapêutica eficaz em diversas patologias crônicas e incapacitantes. ${ }^{1}$

Porém, mesmo sendo um procedimento extremamente eficaz no controle das insuficiências terminais de alguns órgãos e falência de alguns tecidos, a desproporção do número de pacientes em lista de espera versus o número de transplantes é um fato inquestionável. ${ }^{2}$

No Brasil, existem dois tipos de doadores de órgãos e tecidos: doadores em vida que se refere ao indivíduo saudável e disposto a doar um dos órgãos pares ou parte deles, e os doadores cadáveres ou falecidos. Para ser considerado doador post mortem o indivíduo deverá ser diagnosticado com morte encefálica (ME), ou apresentar parada cardiorrespiratória (PCR) recente do qual é possível retirar alguns órgãos, em especial, os rins. $\mathrm{Ou}$ ainda ter diagnóstico de PCR tardia, em até 6 horas, podendo ser doados apenas tecidos. $^{2}$

A ME é um estado em que ocorre a interrupção do funcionamento encefálico, no qual é reconhecido o fator causal e é considerada irreversível. A Associação Americana de Neurologia (AAN) definiu a ME com base em três sinais cardianais, sendo eles ausência de funções encefálicas, incluindo o tronco cerebral, coma e apneia. Essa situação é condição essencial para a extração post mortem dos órgãos e tecidos para transplantes, sendo esse processo regulamentado pela lei 9.434/97 GM que dispõe sobre a remoção de órgãos, tecidos 
e partes do corpo humano para fins de transplante. ${ }^{3}$

O processo de captação de órgãos e tecidos para fins de transplante ocorre pelo menos em oito etapas, sendo a primeira a identificação do potencial doador (PD), segunda a notificação à Central de Notificação Captação e Distribuição de Órgãos e Tecidos (CNCDO); a terceira etapa diz respeito à avaliação do PD com base em sua história clínica, social e viabilidade dos órgãos; na quarta etapa a CNCDO informa à Central Nacional de Transplantes os dados do PD; a quinta etapa é a Ranking dos possíveis receptores, de acordo com o seu cadastro e compatibilidade com o doador; sexta etapa é o contato com a equipe transplantadora, informando sobre a existência de um doador e o possível indivíduo receptor; sétima etapa trata sobre a extração propriamente dita dos órgãos e tecidos no hospital captador e implante no receptor; e última etapa se refere a entrega do corpo do doador, à família. ${ }^{4}$

A família é quem autoriza a doação dos órgãos e tecidos para transplante. A Lei $n^{\circ} 10.211$, publicada em 23 de março de 2001, definiu o consentimento informado como forma de manifestação à doação, sendo que a retirada de órgãos, tecidos e partes do corpo de pessoas falecidas para transplantes ou outra finalidade terapêutica, dependerá da autorização do cônjuge ou parente, maior de idade, obedecida à linha sucessória, reta ou colateral, até o segundo grau inclusive, firmada em documento subscrito por duas testemunhas presentes à verificação da morte. ${ }^{5,6}$

Contudo, a recusa familiar representa um grande entrave à realização dos transplantes, sendo também apontada como um dos grandes fatores responsáveis pela escassez de órgãos e tecidos para transplantes. Fato que está intimamente ligado ao baixo nível de conhecimento dos indivídos do grupo familiar acerca da compreensão do conceito de ME, assim como o entendimento sobre o processo de doação de órgãos e tecidos. ${ }^{7}$

É certo que os meios de comunicação de massa são os principais arquétipos de propagação de informação sobre a temática de doação de órgãos e tecidos, viabilizando informações para a comunidade em geral. Porém, um estudo realizado na Espanha, concluiu que essas informações oriundas da mídia, frequentemente, repassam informações distorcidas, impregnadas de preconceitos e mitos, que não muda a visão dos indivíduos. ${ }^{8}$

A educação em saúde é entendida como uma importante vertente relacionada à aprendizagem, desenhada para alcançar a saúde, voltada a atender a sociedade de acordo com sua realidade, provocando reflexões nos indivíduos, criando 
oportunidades para estes, pensarem e repensarem a sua cultura, e transformarem a sua realidade. Entre os grupos que merecem especial atenção em educação em saúde na atualidade, estão os adolescentes, que, nas últimas décadas tem se tornado publico alvo de estudos e passaram a receber maior atenção em termos de saúde devido às mudanças físicas, psíquicas e sociais próprias da fase, que se configuram em um quadro de vulnerabilidade aos agravos, tanto sociais quanto de saúde. ${ }^{9}$

Os adolescentes, por serem pessoas entre 12 a 19 anos, em intenso processo de reformulação biopsicológica e social, merecem destaque quanto à doação de órgãos, uma vez que podem ser futuros doadores. Eles vivenciam adaptações às mudanças corporais, incluindo modificações no aspecto da sexualidade, que originam crises de angústia expressas em comportamentos, muitas vezes pouco compreendidos; podem perceber sua finitude como inexistente, negando ou desafiando a morte ao se expor a perigos. ${ }^{10}$

Este estudo não tem o objetivo de esgotar o tema, mas sim servir de estopim, fomentando reflexões sobre a temática, construindo uma base teórica com potencial de subsidiar futuras ações como campanhas de esclarecimento em escolas, postos de saúde, clínicas e hospitais, disponibilizando informações claras e concisas acerca dos conceitos básicos que envolvem $\mathrm{o}$ processo de doação e transplante de órgãos e tecidos.

Diante disso buscamos fomentar reflexões sobre a educação em saúde como ferramenta para sensibilizar adolescentes quanto à importância do processo de doação de órgãos e tecidos para transplante, a fim de que estes obtenham o conhecimento do tema e possam também compartilhar em seu meio social promovendo a divulgação e o interesse pelo assunto principalmente entre os familiares, a qual cabe à decisão no momento de autorizar a doação. Dessa forma objetivou-se com o presente estudo analisar o conhecimento dos adolescentes sobre doação e transplante de órgãos antes e após uma ação educativa.

\section{MÉTODO}

Pesquisa descritiva, exploratória com abordagem quanti-qualitativa, alicerçada na Pesquisa-Ação, considerando a população de alunos da educação básica de uma instituição privada de educação infantil de Belém Pará. Todos os alunos do $1^{\circ}$ ano foram convidados a participar da pesquisa. Como critério de inclusão foi considerado a lotação do discente no $1^{\circ}$ ano do ensino médio, de ambos os gêneros, dos turnos matutino e vespertino. Dos 80 discentes, 56,3\% (45) aceitaram participar da pesquisa.

Agendou-se um breve encontro com os alunos em sala de aula, explicitando a 
metodologia e objetivos da pesquisa. Após o esclarecimento das dúvidas sobre o estudo, foi entregue o Termo de Consentimento Livre e Esclarecido (TCLE) com as devidas orientações para ser analisado e assinado pelos pais/responsáveis legais, e o Termo de Assentimento (TA) para ser assinados pelos alunos.

Foi utilizado um questionário estruturado perguntas abertas e fechadas, construído pelos pesquisadores para o alcance das finalidades do estudo e aplicado in loco antes e após a ação educativa, no período de fevereiro a março de 2015. Participaram da coleta de dados, graduandos de enfermagem da Universidade do Estado do Pará (UEPA), previamente capacitados para a aplicação do instrumento de pesquisa.

De posse do questionário e após assinatura do TCLE e o TA, os participantes responderam as perguntas de forma manuscrita, em um tempo de 60 minutos. O questionário foi autoaplicável e se apresentou em três partes: Parte 1 Dados biográficos: idade, gênero, religião, naturalidade, meios de informação e moradia (com quem residia); Parte 2 Questões específicas referentes ao conhecimento sobre o tema: a) O que é a morte encefálica? b) O que é potencial doador de órgãos e tecidos? c) Quais órgãos e tecidos podem ser doados por um doador falecido? e Parte 3 - Questões sobre posicionamentos: a) Você autorizaria sua família a doar seus órgãos após a sua morte? Sim ou Não. Por quê? b) Você autorizaria a doação de órgãos e tecidos de um familiar (mãe, pai, irmãos, tio, outros) para transplante? Sim ou Não. Por quê? c) O tema já foi conversado na sua casa? Caso sim, como foi?

A ação educativa foi realizada por um Enfermeiro Docente e membro da Organização de Procura de Órgãos (OPO) de um centro de referência do Estado. Tratou-se de uma explanação dialogada, em uma linguagem de fácil compreensão, destacando as principais dúvidas e erros das respostas do primeiro questionário, assim como conceitos e importância do tema. Ao término da explanação, que durou em média 1 hora e 30 minutos, os alunos dialogaram entre si e com o Enfermeiro, fazendo questionamentos, expondo dúvidas e socializando experiências. Após a ação educativa, foi entregue aos participantes um novo questionário, com as mesmas perguntas do primeiro.

Após a coleta de dados, seguiu-se para a análise comparativa das respostas antes e após a ação educativa. O processamento estatístico foi realizado nos softwares GrafTable versão 2.0 e BioEstat versão 5.3. Foi realizado o teste Quiquadrado de aderência. Para a análise das 
informações de natureza qualitativa utilizou-se a análise descritiva, sendo as falas representadas por códigos alfa numéricos com as seguintes denominações: "Aluno 1", “Aluno 2"... respectivamente. A pesquisa foi realizada de acordo com os pressupostos que regulamentam pesquisa envolvendo seres humanos contidas na resolução $n^{\circ}$ 466/2012 do Conselho Nacional de Saúde.

O estudo foi aprovado pelo Comitê de Ética em Pesquisa (CEP) do curso de Graduação em Enfermagem da Universidade do Estado do Pará (UEPA), CAAE: 39511514.7.0000.5170, número do parecer: 923.382, com autorização prévia da instituição e posterior assinatura do TCLE e TA pelos participantes da pesquisa.

\section{RESULTADOS}

\section{PARTE 1: DADOS BIOGRÁFICOS}

A idade variou de 13 a 17 anos, sendo a maioria $(51,1 \%)$ com faixa etária de 14 anos. A maioria dos participantes 26 $(57,8 \%)$ era do gênero feminino, de religião católica $33(73,3 \%)$, e todos de naturalidade paraense 45 (100\%). O principal meio de informação utilizado foi a internet $24(53,3 \%)$. Com relação à moradia, a maioria dos adolescentes relatou residir com pais/irmãos 39 (86,7\%) conforme Tabela 1.

Tabela 1: Dados Biográficos de $n=45$ adolescentes. Belém/PA, ano 2015. 


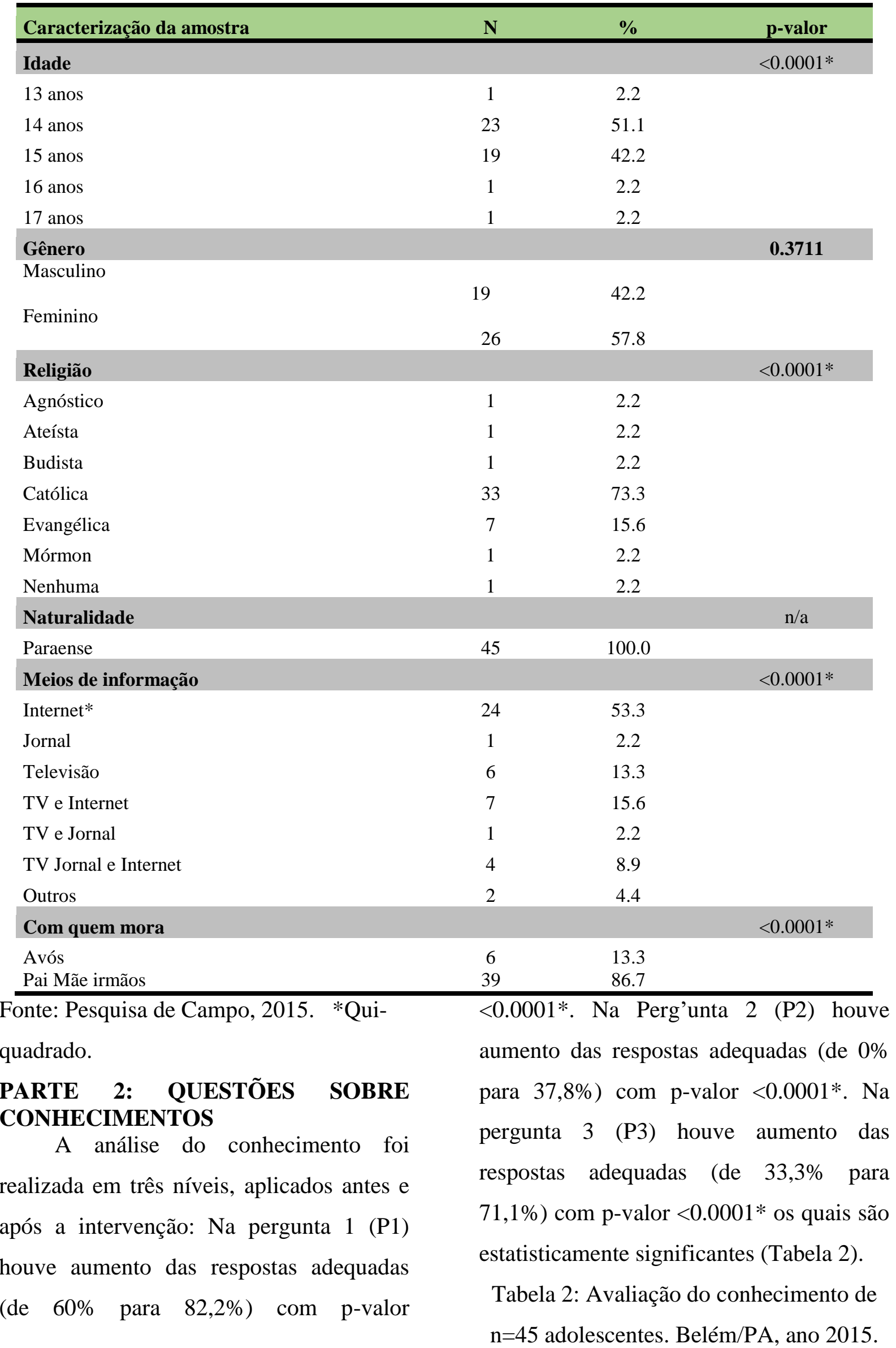




\begin{tabular}{|c|c|c|c|c|}
\hline \multicolumn{5}{|c|}{ Classificação das Respostas } \\
\hline Conhecimento & Adequada & Parcial & Inadequada & p-valor \\
\hline \multicolumn{2}{|c|}{ P1- O que é a morte encefálica? } & & $0.0011 *$ & \\
\hline \multirow[t]{2}{*}{ Antes } & 27 & 7 & 11 & \\
\hline & $60.0 \%$ & $15.6 \%$ & $24.4 \%$ & \\
\hline \multirow[t]{2}{*}{ Depois } & 37 & 2 & 6 & \\
\hline & $82.2 \% *$ & $4.4 \%$ & $13.3 \%$ & \\
\hline \multicolumn{3}{|c|}{ P2 - O que é potencial doador de órgãos e tecidos? } & $<0.0001 *$ & \\
\hline \multirow[t]{2}{*}{ Antes } & 0 & 6 & 39 & \\
\hline & $0.0 \%$ & $13.3 \%$ & $86.7 \%$ & \\
\hline \multirow[t]{2}{*}{ Depois } & 17 & 10 & 18 & \\
\hline & $37.8 \% *$ & $22.2 \%$ & $40.0 \%$ & \\
\hline
\end{tabular}

P3 - Quais órgãos e tecidos podem ser doados por um doador cadáver?

\begin{tabular}{lccc} 
& & $<0.0001 *$ \\
Antes & 15 & 20 & 10 \\
Depois & $33.3 \%$ & $44.4 \%$ & $22.2 \%$ \\
& 32 & 9 & 4 \\
\hline
\end{tabular}

Fonte: Pesquisa de Campo, 2015. *Qui-quadrado de aderência.

Quando questionados sobre o conceito de morte encefálica, $60 \%$ dos adolescentes apresentaram respostas adequadas antes da educação em saúde, e uma parcela significativa dos mesmos $(82,2 \%)$ após a ação educativa respondeu corretamente que morte encefálica ocorre quando o cérebro não funciona mais, mas o coração e os pulmões podem ainda estar funcionando.

Sobre o conceito de potencial doador nenhum adolescente respondeu adequadamente, sendo a maioria $86,7 \%$ com respostas inadequadas antes da educação em saúde. Porém, após a ação houve aumento de $37,8 \%$ de respostas adequadas, mostrando a relevância de se investir na educação em saúde voltada para o esclarecimento do tema.

Quando perguntado aos adolescentes quais órgãos poderiam ser doados, apenas 33,3\% responderam adequadamente. Após a educação, houve aumento significativo para $71,1 \%$. Tal aumento atribui-se a educação realizada, onde foi abordado a quantidade de órgãos que um indivíduo em ME pode doar.

\section{QUESTÃO SOBRE DÚVIDAS}

Antes da intervenção cerca de 81,3\% dos adolescentes apresentavam alguma dúvida, entre elas a mais frequente foi sobre o processo de doação de órgãos e tecidos $(24,4 \%)$. Depois da intervenção 77,8\% não apresentaram dúvidas (Gráfico 1).

Gráfico 1: Dúvidas antes e após a educação em saúde. Belém/PA, ano 2015. 


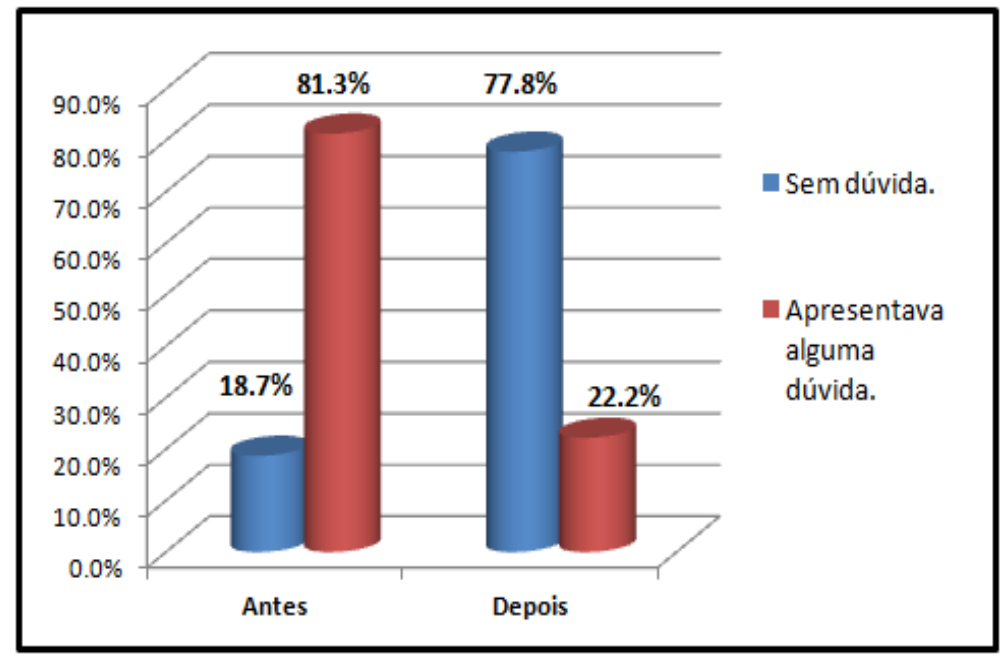

Quanto autorizar a doação de órgãos

Fonte: Pesquisa de Campo, 2015.

\section{PARTE 3: QUESTÕES SOBRE POSICIONAMENTOS}

Houve aumento de 73,3\% para $86,7 \%$ quando questionados se doariam seus órgãos após sua morte. E de 68,9\% para $75,6 \%$ quando questionados se consentiriam a doação de órgãos de um familiar, mostrando que a maioria dos participantes são favoráveis à doação.

Antes da educação em saúde: [...] Não doaria porque eu sinto como se algo fosse tirado de mim, apesar de morta, a ideia me parece um pouco assustadora (ALUNO 43); Depois da educação em saúde: Doaria porque a doação de órgãos ajuda aqueles que precisam e necessitam de algum órgão (ALUNO 43).

Antes da educação em saúde: não doaria meus órgãos, porque não me sentiria bem sabendo que fui enterrado sem órgãos (ALUNO 44); Depois da educação em saúde: doaria, porque depois de morto eu não vou mais precisar então é melhor doar (ALUNO 44). de um familiar, também houve aumento no consentimento após a ação educativa. No entanto o que nos chamou a atenção foram às respostas daqueles que não autorizariam, sendo justificado na maioria das respostas por não conhecer a vontade do familiar, como pode ser observado nas falas a seguir: [...] Essa seria a decisão de cada um! (ALUNO 21); apenas se eles quisessem! (ALUNO 27); só se for por escolha deles! (ALUNO 31).

Quando questionado se haviam conversado sobre o tema doação e transplante de órgãos com a família, o resultado se manteve inalterado antes e após a educação, onde somente $24,4 \%$ haviam discutido o assunto com os familiares.

\section{DISCUSSÃO}

O percentual de católicos foi de $73 \%$. Estes dados corroboram com os dados estatísticos do perfil da população brasileira do Instituto Brasileiro de 
Geografia e Estatística (IBGE) ${ }^{11}$, que por sua vez demonstra que $64,6 \%$ da população brasileira se declararam católica, sendo a segunda maior porcentagem composta por evangélicos (22\%).

$\mathrm{Na}$ literatura parece haver uma tendência de que a religião sem dúvida é fator importante que interfere na opinião das pessoas acerca da doação de órgãos e tecidos para transplantes. Contudo, isso depende da doutrina pertencente a cada crença religiosa que diferem entre si. Ressalta-se que nenhuma religião é totalmente contrária à doação de órgãos e tecidos para fins de transplante. Salienta-se a religião testemunhas de Jeová, que se posiciona de maneira contrária somente com relação à doação de sangue. Pontua-se que apesar da maioria das religiões serem favoráveis ao processo de doação, ainda assim a religiosidade é fator determinante na tomada de decisões, considerando a crença do familiar na ocorrência de um milagre com o retorno à vida do paciente. ${ }^{12}$

Assim, observamos que apesar da religião do PD ou do familiar do PD ser determinante para influenciar na tomada de decisões, contudo o que se observa é que quase a totalidade da amostra constitui-se de participantes que possuem religião favorável ao processo de doação e transplante. Reiteramos que por mais que a religião se apresente como um fator importante, não configura um entrave para o consentimento familiar. ${ }^{13}$

Em relação à moradia, a maioria $(86,7 \%)$ dos adolescentes reside com pais, avós e irmãos. Dado importante, pois podemos inferir que a maioria das opiniões, crenças e valores expressos pelos estudantes podem retratar, também, as concepções dos familiares.

Diversos fatores além da falta de conhecimento interferem na não concretização da doação, como a diversidade cultural e religiosa. ${ }^{14} \mathrm{~A}$ família exerce um papel fundamental na etapa de crescimento e desenvolvimento do adolescente propiciando o equilíbrio do indivíduo, já que ela é o primeiro vínculo de inter-relação com o seu meio social, além de nortear os valores e os princípios morais que os adolescentes vão seguir por toda a vida, ainda que possam reformular alguns preceitos familiares herdados. ${ }^{10}$

$\mathrm{Na}$ maioria dos casos, a escassez de órgãos para transplante é atribuída à falta de informação da população e às falhas no Sistema Único de Saúde (SUS) no processo de captação de órgãos. Contudo, esta carência também se deve a outros fatores, dentre eles, os problemas culturais, a demora no diagnóstico de $\mathrm{ME}$ e recusa da familiar. ${ }^{15}$ Dados da Associação Brasileira de Transplantes de Órgãos $(\mathrm{ABTO})^{16}$ apontam que $44 \%$ das doações 
que não são efetivadas se devem a recusa da família.

O principal meio de obtenção de informação foi à internet. $\mathrm{O}$ que se observa é o crescente interesse da mídia em apresentar à sociedade o tema transplante de órgãos e tecidos. Porém, na maioria das vezes ocorre à transmissão de informações em noticiários de forma exagerada e sensacionalista em detrimento da falta de programas esclarecedores sobre o assunto, pouco ajudando na eliminação de mitos, o que contribui negativamente para $o$ processo. $^{17}$

Neste sentido, observa-se que embora as propagandas existentes na televisão objetivem estimular a doação, são insuficientes para os esclarecimentos de dúvidas. Com relação à internet, constituise importante meio de comunicação, considerando a gama de informações existente a respeito do tema, mas sem dúvida, reconhecemos que a abordagem individual através de ações educativas possuem mais receptividade para a construção de opiniões, considerando a possibilidade de ocorre o feedback, isto é, devolutiva da informação aos indivíduos, com a possibilidade de retirada de dúvidas e esclarecimentos.

Estudo com estudantes de graduação em enfermagem demonstrou que $41 \%$ dos entrevistados não tinham acesso a informações sobre o tema, os demais afirmaram obter conhecimento por meio da televisão, sendo esta um importante meio de repasse de informações em massa. ${ }^{18}$ Apesar da televisão atingir um grande contingente populacional, estudos mostram que os adolescentes preferem receber informações nas disciplinas do desenho curricular, principalmente no componente curricular de biologia, além de estratégias de divulgação como panfletos ou outros materiais informativos. ${ }^{19}$

Um estudo realizado com 108 estudantes do ensino médio da rede publica e privada de Gurupi-TO, demonstraram que a divulgação acerca da doação de órgãos e tecidos para transplante ainda é insuficiente entre adolescentes. ${ }^{19}$

No que tange ao conhecimento acerca da ME, PD e órgãos que podem ser doados, observou-se um aumento estatisticamente significativo das respostas adequadas após a ação educativa, o que confirma que a educação em saúde serve como promoção do conhecimento e esclarecimento, fazendo com que os indivíduos obtenham maior informação, despertando o interesse pelo assunto e discussão em seu meio social. Resultado satisfatório, haja vista que, entendemos ser de suma importância que a sociedade entenda o que é ME e seja esclarecida sobre o processo de doação e transplante, de modo que a dúvida ou o desconhecimento sobre o assunto não 
interfira negativamente no momento de consentir ou não uma doação.

O conceito de ME é um dos temas mais complexos e controversos. ${ }^{10}$ Desta forma, ressalta-se a importância de a sociedade receber informações precisas e transmiti-las de forma adequada às gerações mais novas. ${ }^{9}$ No entanto, uma pesquisa sobre programas educativos no ensino médio mostrou que o tema em pauta não faz parte das atividades escolares, corroborando a necessidade de as informações serem transmitidas através da inserção do conteúdo nos desenhos curriculares. $^{20}$

Sobre o conceito de PD nenhum adolescente respondeu adequadamente, antes da educação em saúde. Porém, após a ação houve aumento de $37,8 \%$ de respostas adequadas, mostrando a relevância de se investir na educação em saúde voltada para o esclarecimento do tema.

Quanto aos órgãos e tecidos que podem ser doados e o tempo máximo de preservação extracorpórea respectivamente são: córneas até 7 dias, coração e pulmões de 4 a 6 horas, rins até 48 horas, fígado e pâncreas de 12 a 24 horas, e ossos até 5 anos. $^{2}$

Quando questionados se doariam seus órgãos após sua morte, e se consentiriam a doação de órgãos de um familiar. Os motivos pelos quais são favoráveis são variáveis, sendo os principais ajudar ao próximo e salvar vidas. Quanto ao principal motivo para não doar foi não ter pensado no assunto.

Diante disso, entendemos que a educação transforma as pessoas e suas atitudes, pois trás conhecimentos, visões novas, capazes de modificar comportamentos. Fica evidente que após a ação os adolescentes adquiriram um pensamento crítico e reflexivo, denotando capacidade de tomar decisões, exercendo sua autonomia.

Quanto a autorizar a doação de órgãos de um familiar, também houve aumento no consentimento após a ação educativa. Contudo o que nos chamou a atenção, foram às respostas daqueles que não autorizariam, sendo justificado na maioria das respostas por não conhecer a vontade do familiar. Por esse motivo é de crucial importância à discussão prévia sobre o assunto no contexto familiar, para que o indivíduo expresse em vida seu desejo ou não de ser um doador, uma vez que a vontade é dele, mas a decisão é da família.

Quanto à discussão prévia do assunto com os familiares, quando questionados se já haviam conversado sobre o tema doação e transplante de órgãos com a família, o resultado continuou o mesmo antes e após a ação a educativa. Este dado merece ser colocado em destaque, haja vista que, mesmo a maioria dos adolescentes se 
manifestarem favoráveis a doação de seus órgãos, estes não expressaram esse desejo para suas famílias, o que diminui a probabilidade de consentimento da doação.

Sobre o impacto das intervenções educativas no posicionamento dos adolescentes quanto à doação de órgãos e tecidos, fica explícito que a educação em saúde pode revelar-se como instrumento eficaz nesse contexto, possibilitando a troca entre o conhecimento científico e popular, incentivando não só a busca pelo conhecimento, mas também despertando o interesse pelo tema e a discussão no meio social e familiar.

Pensamos que o resultado foi satisfatório, ressaltando que a educação em saúde é o principal meio divulgador de informação e esclarecedor de dúvidas. Acredita-se que através da disseminação do conhecimento e maior grau de esclarecimento, torna-se possível à mudança da realidade dos números de doações no Brasil. ${ }^{14}$

\section{CONCLUSÃO}

Os resultados contemplaram a hipótese positiva sugerida durante a construção do projeto de pesquisa, confirmando que a educação em saúde é uma grande aliada na promoção de doação de órgãos e tecidos. Após a ação em saúde, houve o aumento no nível de conhecimento sobre o assunto, diminuição nas dúvidas existentes e mudanças no posicionamento, optando a maioria em ser doador e consentir a doação.

Emergiram algumas concepções, como o desejo altruísta em salvar a vidas através da doação de órgãos e tecidos. Contudo, dúvidas e inseguranças revelaram-se como sentimentos que podem interferir na tomada de decisão de doar. Esperamos que os medos e tabus minimizem, possibilitando que o desejo de exercer a solidariedade, tão enfatizado pelos pesquisados, se concretize na prática, diminuindo o tempo de espera e sofrimento daqueles que dependem da doação.

As informações veiculadas pelos meios de comunicação de massa não têm sido suficientes nem eficientes para modificar comportamentos, ao contrário, reforçam o imaginário popular repleto de mitos, crendices e desinformações sobre a atividade relacionada aos processos que envolvem a doação de órgãos e tecidos. Nesse ínterim, a intervenção educativa é uma oportunidade de troca de experiências entre sujeitos, possibilitando-lhes o acesso a informações e a trocas de vivências pessoais, comumente carregadas de conflitos e dificuldades que interferem na escolha de doar ou não os órgãos de um ente querido. 
Diante dos dados encontrados neste estudo, se visualiza a necessidade do estabelecimento de programas planejados e delineados dentro de um processo educativo contínuo, destinados a todos os segmentos da sociedade, inclusive dentro do contexto da educação básica.

A discussão familiar sobre o tema é deficitária, sendo necessário incentivar as pessoas dispostas à doação, compartilharem esta decisão com seus familiares. A sociedade precisa compreender que a doação depende exclusivamente da autorização familiar favorecendo o crescimento do número de transplantes e aumentando, consequentemente, a sobrevida dos pacientes que aguardam nas filas de transplante.

A despeito da relevância deste tema ressalta-se que o presente estudo foi desenvolvido em apenas uma instituição de ensino básico do município de Belém, Estado do Pará, o que pode representar a limitação para inferências destas perspectivas em outros níveis de atenção à saúde. Contudo, esta pesquisa pode contribuir com informações relevantes para o conhecimento e análise de práticas educativas como uma grande aliada na promoção de doação de órgãos e tecidos para transplante.

Devido à importância social que representa a doação de órgãos e tecidos, acreditamos que estratégias de esclarecimento tanto para os profissionais, como para a sociedade em geral poderão contribuir para a sobrevida de milhares de pacientes que aguardam na fila por um transplante. Recomendamos que a temática seja inserida nos desenhos curriculares dos cursos de graduação, para formar profissionais capacitados e preparados para lidar com as demandas sociais, e com os questionamentos e dúvidas da comunidade na qual estão inseridos, abrindo espaço para discussão e elaboração de novos estudos.

\section{REFERÊNCIAS}

1. Nogueira MA, Leite CRA, Reis Filho EV, Medeiros LM. Vivência das Comissões Intra-hospitalares de doação de órgãos/tecidos para transplante. Rev Cient Enferm [internet]. 2015 [citado em: $25 \mathrm{dez}$ 2015]; 5(14): 5-11. Disponível em: http://www.recien.com.br/index.php/Recie n/article/view/105/169

2. Associação Brasileira de Transplantes. ABTO. Registro Brasileiro de Transplantes. Dimensionamento dos Transplantes no Brasil e em cada Estado (2007-2014) [Internet]. São Paulo (SP): 2014. [citado em: 21 de jun 2016]. 85 p. Disponível em: http://www.abto.org.br/abtov03/Upload/fil e/RBT/2014/rbt2014-lib.pdf

3. Kumar L. Brain death and care of the organ donor. $\mathrm{J}$ Anaesthesiol Clin Pharmacol [internet]. 2016 [citado em: 21 de jun 2016]; 32(2): 146-152. Disponível em:

http://www.ncbi.nlm.nih.gov/pmc/articles/ PMC4874065/?report=printable

4. Negreiros FDS, Marinho AMCP, Garcia JHP, Morais APP, Aguiar MIF, Carvalho 
SL. Captação do fígado do doador para transplante: uma proposta de protocolo para o enfermeiro. Escola Anna Nery Rev de Enferm [internet]. 2016 [citado em: 18 jun 2016]; 20(1): 38-47. Disponível em: http://www.scielo.br/pdf/ean/v20n1/14148145-ean-20-01-0038.pdf

5. Fernandes MEN, Bittencourt ZZLC, Boin IFSF. Vivenciando a doação de órgãos: sentimentos de familiares pós consentimento. Rev Latino-Americ de Enferm [internet]. 2015 [citado em: 18 jun 2016]; 23(5): 895-901. Disponível em: http://www.scielo.br/pdf/rlae/v23n5/pt_01 04-1169-rlae-23-05-00895.pdf

6. Maynard LOD, Lima IMSO, Lima YOR, Costa EA. Os conflitos do consentimento acerca da doação de órgãos post mortem no Brasil. Rev de Direito Sanit São Paulo [internet]. 2016 [citado em: 25 jun 2016]; 16(3): 122-144. Disponível em: http://www.revistas.usp.br/rdisan/article/vi ew/111657/109688

7. Pessoa JLE, Schirmer J, Roza BA. Avaliação das causas de recusa familiar a doação de órgãos e tecidos. Acta Paul Enfem [internet]. 2013 [citado em: 18 jun 2016]; 26(4): 323-330. Disponível em: http://www.scielo.br/pdf/ape/v26n4/v26n4 a05.pdf

8. Morais TR, Morais MR. Doação de órgãos: é preciso educar para avançar. Rev Saúd em Debate [internet]. 2012 [citado em: 20 jun 2016]; 36(95): 633-639. Disponível em: http://www.scielo.br/pdf/sdeb/v36n95/a15 v36n95.pdf

9. Cossa APP, Jardim DP. O enfermeiro na educação em saúde na adolescência nos últimos dez anos. Rev Enferm UNISA [internet]. 2011[citado em: 20 jun 2016]; 12(1): 58-63. Disponível em: http://www.unisa.br/graduacao/biologicas/ enfer/revista/arquivos/2011-1-10.pdf 10. Monteiro AMC, Fernandes EC, Araújo EC; Cavalcanti AMTS, Vasconcelos MGL. Doação de órgãos: compreensão na perspectiva de adolescentes. Rev Bras Saúd Matern.
Infant Recife [internet]. 2011[citado em: 20 jun 2016]; 11(4): 389-396. Disponível em:

http://www.scielo.br/pdf/rbsmi/v11n4/v11 n4a05.pdf

11. Instituto Brasileiro de Geografia (IBGE). Ministério do Planejamento, orçamento e gestão. Censo Demográfico 2010: características gerais da população, religião e pessoas com deficiência [Internet]. Rio de Janeiro (RJ): 2010. [citado em: 21 de jun 2016]. 2011 p. Disponível em: http://biblioteca.ibge.gov.br/visualizacao/p eriodicos/94/cd_2010_religiao_deficiencia. pdf

12. Santos MJ, Massarollo MCKB. Fatores que facilitam a entrevista no processo de doação de órgãos e tecidos para transplante. Acta Paul Enferm [internet]. 2011 [citado em: 22 dez 2016]; 4(24): 472-478. Disponível em: http://www.scielo.br/pdf/ape/v24n4/a05v2 4n4.pdf

13. Rodrigues CFA, Stychnicki AS, Boccalon B, Cezar GS. Morte encefálica, uma certeza? O conceito de "morte cerebral" como critério de morte. Rev Bioethikos [internet]. 2013 [citado em: 22 dez 2016]; 7(3): 271-281. Disponível em: http://www.saocamilo-

sp.br/pdf/bioethikos/105/1811.pdf

14. Ferrazzo S, Vargas MAO, Mancia JR, Ramos FRS. Crença religiosa e doação de órgãos e tecidos: revisão integrativa da literatura. Rev de Enferm da UFSM [internet]. 2011 [citado em: 17 nov 2015]; 1(3):449-460. Disponível em: https://periodicos.ufsm.br/reufsm/article/vi ew/2790/2410

15. Ana LM, Adelaide MR, João PAFF, Maria HB, Michelle BR, Mithla BO. Análise das dificuldades no processo de doação de órgãos: uma revisão integrativa da literatura. Rev Bioethikos [internet]. 2010 [citado em: 17 nov 2015]; 4(1): 6674. Disponível em: http://www.saocamilosp.br/pdf/bioethikos/73/66a74.pdf

16. Associação Brasileira de Transplantes de Órgãos (ABTO). Registro Brasileiro de 
Transplantes (RBT) [internet]. 2015 [citado em: 17 nov 2016]. Disponível em: http://www.abto.org.br/abtov03/default.asp $\mathrm{x} ? \mathrm{c}=1077$

17. Pruinelli L, Kruse MHL. Mídia e doação de órgãos: a produção de sujeitos doadores. Rev Gaúcha Enferm [internet]. 2012 [citado em: 22 dez 2016]; 33(4): 8693. Disponível em: http://www.scielo.br/pdf/rgenf/v33n4/11.p df

18. Soares LM, Leite RG, Rocha FCV. Conhecimento dos graduandos de uma instituição de ensino superior sobre a doação de órgãos. Rev Interd [internet]. 2015 [citado em: 17 nov 2016]; 8(2): 158168. Disponível em: http://revistainterdisciplinar.uninovafapi.ed u.br/index.php/revinter/article/view/505/pd f_218

19. Brandão TS, Mota N, Pizzolato AS. Conhecimento de estudantes de ensino médio da rede particular e pública a respeito de transplante e doação de órgãos e tecidos. Rev Amazôn Scien \& health [internet]. 2016 [citado em: 17 nov 2015]; 4(1): 2-9. Disponível em: http://ojs.unirg.edu.br/index.php/2/article/v iew/182/405

20. Santos MJ, Massarollo MCKB, Moraes EL. Entrevista familiar no processo de doação de órgãos e tecidos para transplante. Acta Paul Enferm [internet]. 2012 [citado em: 20 nov 2015]; 25(5): 788-94. Disponível em: http://www.scielo.br/pdf/ape/v25n5/22.pdf

Recebido em 26/02/2016

Aprovado em 21/12/2016

Publicado em 29/12/2016 